\title{
Comportamiento de las calizas «griotte» carboníferas frente a deformaciones compresivas en dos localidades de la Zona Cantábrica (NO de la Península Ibérica): resultados preliminares
}

\section{Behaviour of the Carboniferous «griotte» limestones under compressive deformation in two localities of the Cantabrian Zone (NW Iberian Peninsula): preliminary results}

\author{
M. Bulnes ${ }^{\mathrm{I}}$, J. Poblet ${ }^{\mathrm{I}}$, Á. De Ana ${ }^{\mathrm{I}}$, y M. Masini² \\ ${ }^{1}$ Departamento de Geología, Universidad de Oviedo, C/Jesús Arias de Velasco s/n, 33005 Oviedo, España, UE \\ (e-mail:maite@geol.uniovi.es,jpoblet@geol.uniovi.es,a.da.cubero88@gmail.com) \\ ${ }^{2}$ Repsol, 2455 Technology Forest Boulevard, The Woodlands, Houston, TX 77381, Estados Unidos \\ (e-mail: massimiliano.masini@repsol.com)
}

\begin{abstract}
Resumen: Se han analizado y comparado las características y posible evolución de las estructuras desarrolladas en la Fm. Alba, o caliza "griotte» carbonífera, en dos afloramientos ubicados en unidades estructurales distintas de la Zona Cantábrica, uno situado en los alrededores de San Emiliano y el otro en las playas de La Ballota y de Andrín. En ambos, la Fm. Alba acomoda deformación en distintos grados mediante el desarrollo de varios tipos de mesoestructuras. Se ha encontrado una serie de similitudes y diferencias entre los afloramientos tanto desde el punto de vista estratigráfico, como estructural. Aparentemente, las características estratigráficas distintas podrían haber sido el factor que ha ejercido una mayor influencia en el comportamiento mecánico a nivel mesoestructural dentro de la Fm. Alba.
\end{abstract}

Palabras clave: calizas «griotte» carboníferas, Zona Cantábrica, pliegues, cabalgamientos.

Abstract: We have analysed and compared the features and possible evolution of the structures developed within the Alba Fm., or Carboniferous «griotte» limestone, in two outcrops located in different structural units of the Cantabrian Zone: around San Emiliano and on La Ballota and Andrín beaches. In both outcrops the Alba Fm. accommodates deformation in various degrees by developing different types of mesostructures. We found a number of similarities and differences between the outcrops from the stratigraphic and structural point of view. Apparently, the different stratigraphic features might have been the factor that had exerted a greater influence on the mechanical behaviour at mesostructural scale within the Alba Fm.

Keywords: Carboniferous «griotte» limestones, Cantabrian Zone, folds, thrusts. 
Es bien conocido que las propiedades mecánicas de las rocas deformadas, en relación con la presencia de contrastes de competencia en la sucesión estratigráfica, parece tener una gran influencia tanto en la geometría final como en la evolución de muchos tipos de estructuras tectónicas ya sea a pequeña escala, como por ejemplo pliegues individuales (ver por ejemplo Ramsay y Huber, 1987, p. 387-402), hasta gran escala, como cinturones de pliegues y cabalgamientos (ver por ejemplo Colman-Sadd, 1978).

En la sucesión estratigráfica, fundamentalmente de edad paleozoica, deformada por el cinturón varisco de pliegues y cabalgamientos desarrollado en la Zona Cantábrica (Fig. 1), existe una unidad estratigráfica denominada Fm. Alba (Comte, 1959) o Fm. Genicera (Wagner et al., 1971), o más informalmente caliza «griotte» carbonífera. Esta formación, de edad Carbonífera y poco espesor, corresponde a un conjunto de calizas, radiolaritas y pizarras. El com- portamiento de esta unidad estratigráfica a escala mesoestructural frente a los esfuerzos tectónicos que sufrió es variable, siendo en ocasiones prácticamente idéntico al que muestran unidades estratigráficas más competentes y en otras muy diferente, comportándose como una unidad incompetente (ver por ejemplo Martínez Álvarez, 1965). En algunas localidades da lugar a un despegue, de forma que las rocas suprayacentes poseen una estructura distinta a las infrayacentes.

A raíz de estas observaciones cabe preguntarse sobre las razones por las que en algunas localidades la Fm. Alba se comporta de forma incompetente y en otras no, si en las ocasiones en que la Fm. Alba se comporta de manera incompetente sigue siempre un mismo patrón estructural y en caso contrario qué motivaría ese comportamiento distinto. En este trabajo, se pretende contribuir a resolver algunas de estas cuestiones, mostrando y comparando las características

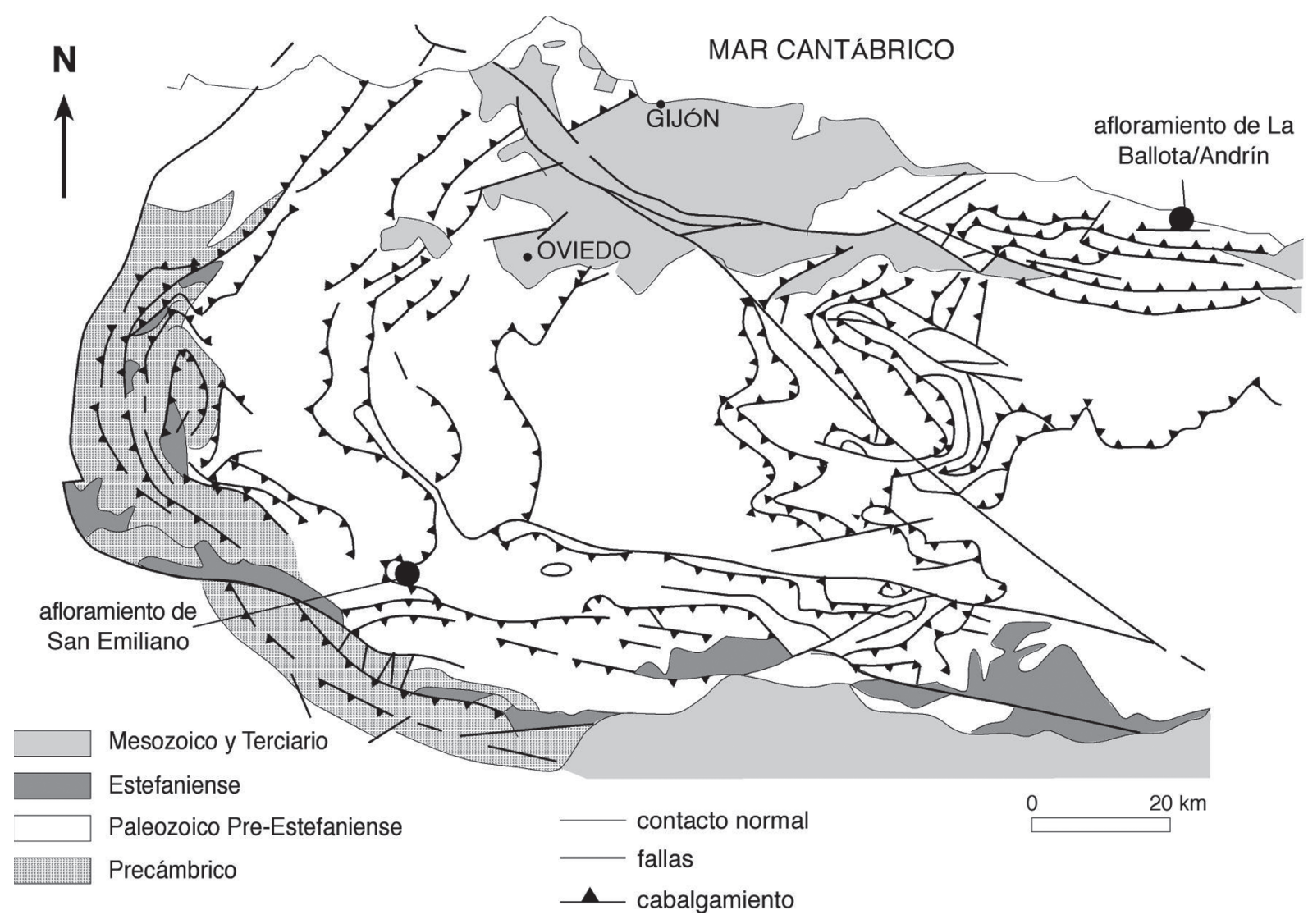

Figura 1. Esquema estructural de la Zona Cantábrica en el que se indica la ubicación de los dos afloramientos estudiados: San Emiliano y playas de La Ballota y de Andrín. 
de las estructuras desarrolladas en el seno de esta unidad estratigráfica en dos afloramientos ubicados en unidades estructurales distintas en los que la Fm. Alba acomoda deformación en distintos grados mediante el desarrollo de varios tipos de mesoestructuras. El comportamiento relativamente dúctil de la Fm. Alba en ambas localidades fue puesto de manifiesto con anterioridad por algunos autores, tanto en el afloramiento ubicado en la zona de San Emiliano, en la parte suroeste de la Zona Cantábrica (Masini, 2007; Masini et al., 2010a y 2010b), como en el de la zona de las playas de La Ballota y de Andrín, en la porción noroeste de la Zona Cantábrica (Barrois, 1882; Martínez-García et al., 1981; de Ana, 2015).

\section{Situación geológica}

La Zona Cantábrica es el nombre con el que se conoce al cinturón de pliegues y cabalgamientos que forma la zona externa del orógeno varisco en el noroeste de la Península Ibérica (Lotze, 1945; Julivert et al., 1972) (Fig. 1). En sección, este cinturón muestra la típica morfología de cuña orogénica que se adelgaza hacia el antepaís, es decir, hacia el este, mientras que en mapa, las estructuras tienen un trazado curvo (Arco Ibero-Armoricano o Astúrico). En la Zona Cantábrica se ha documentado la existencia de distintos sistemas de cabalgamientos y de diferentes tipos de pliegues relacionados con ellos (Julivert, 1971, 1979, 1981, 1983; Savage, 1979, 1981; Pérez-Estaún et al., 1988; Pérez-Estaún y Bastida, 1990; Alonso et al., 1992, 2009; Aller et al., 2004; entre otros). En algunos puntos de este cinturón, tanto los cabalgamientos como los pliegues relacionados con estos están muy verticalizados, llegando incluso a estar invertidos, por lo que, aunque la mayoría de las estructuras son coherentes con un vector de transporte tectónico dirigido hacia el antepaís, su disposición hace que tengan un desplazamiento aparente hacia el interior de la cordillera.

La Fm. Alba es una de las unidades estratigráficas de edad carbonífera (Tournaisiense tardío- Serpukhoviense) (ver por ejemplo Adrichem Boogaert, 1965; Higgins, 1974; Menéndez Álvarez, 1978, 1991; Wagner Gentis, 1980; Belka y Lehman, 1998) más extendidas en toda la Zona Cantábrica, que aparece en distintas unidades estructurales y en distin- tas posiciones estructurales dentro de los pliegues y cabalgamientos que conforman la estructura de esta región (ver entre otros los mapas geológicos de síntesis de Alonso, 1989; Alonso et al., 1989; Álvarez-Marrón et al., 1989; Bastida y Gutiérrez, 1989; Marquínez, 1989). La sucesión más completa de la Fm. Alba consiste en unas pocas decenas de metros de calizas nodulosas rojizas, radiolaritas y pizarras y calizas grises ordenadas de tal forma que los materiales silíceos separan una unidad carbonatada a muro de otra a techo. Wagner et al. (1971) denominaron a estas unidades como miembros Gorgera, Lavandera y Canalón respectivamente. No obstante, no siempre aparecen todos estos términos de la sucesión y su espesor puede ser variable. Posteriormente se han definido otros miembros dentro de la Fm. Alba (ver por ejemplo Kullman et al., 1977; García López y Sanz López, 2002). En la mayor parte de la Zona Cantábrica, esta formación está recubierta por las calizas de grano fino de la Fm. Barcaliente, también de edad carbonífera. Sin embargo, se dispone sobre unidades estratigráficas distintas en función de su ubicación; así, puede aparecer sobre las pizarras negras carboníferas de la Fm. Vegamián, sobre las calizas carboníferas de la Fm. Candamo o Baleas o sobre las areniscas devónicas de la Fm. Ermita (ver por ejemplo Sánchez de Posada et al., 1990; Fernández, 1995; Colmenero et al., 2002; Fernández et al., 2004).

El afloramiento más meridional estudiado de la Fm. Alba corresponde a un talud subvertical de unas pocas decenas de metros de largo y varios metros de alto situado en el margen de una carretera de orientación aproximada N-S que une la localidad de San Emiliano al norte con Puente Orugo al sur, en la provincia de León (Fig. 2). Este afloramiento se encuentra en la parte suroeste de la Zona Cantábrica y en la rama meridional del Arco Astúrico, donde las estructuras orientadas E-O son las predominantes. Más concretamente, el afloramiento se sitúa en el flanco norte, fuertemente inclinado hacia el norte, del anticlinal de Huergas-Valgrande (Marcos, 1968), también conocido como anticlinal de Villasecino (Alonso et al., 1989) (ver por ejemplo los mapas y cortes geológicos de De Sitter, 1962; Marcos, 1968; Martínez-Álvarez et al., 1968; Alonso et al., 1989; Rodríguez-Fernández et al., 1990; Instituto Geológico y Minero de España, 2005-2011). 
a)

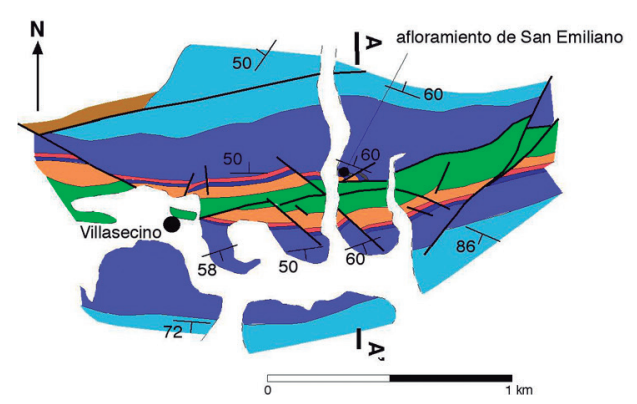

b)

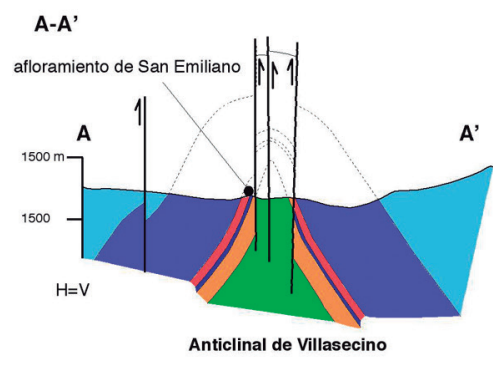

Figura 2. a) Mapa geológico de los alrededores del afloramiento de San Emiliano (modificado de Rodríguez-Fernández et al., 1990 por Masini et al., 2010a) y b) corte geológico del anticlinal de Villasecino. En ambos se ubica la posición estructural de la zona estudiada (modificado de Masini et al., 2010a). Esta región está ubicada en el esquema estructural de la figura 1.

El afloramiento más septentrional estudiado de la Fm. Alba se sitúa en los acantilados de las playas de La Ballota y de Andrín, y presenta unas decenas de metros de altura y unas centenas de metros de longitud, estando orientados aproximadamente en dirección NO-SE. Ambas playas se ubican al nor-noreste de la localidad de Andrín (Fig. 3). Desde el punto de vista geológico estos aflora-

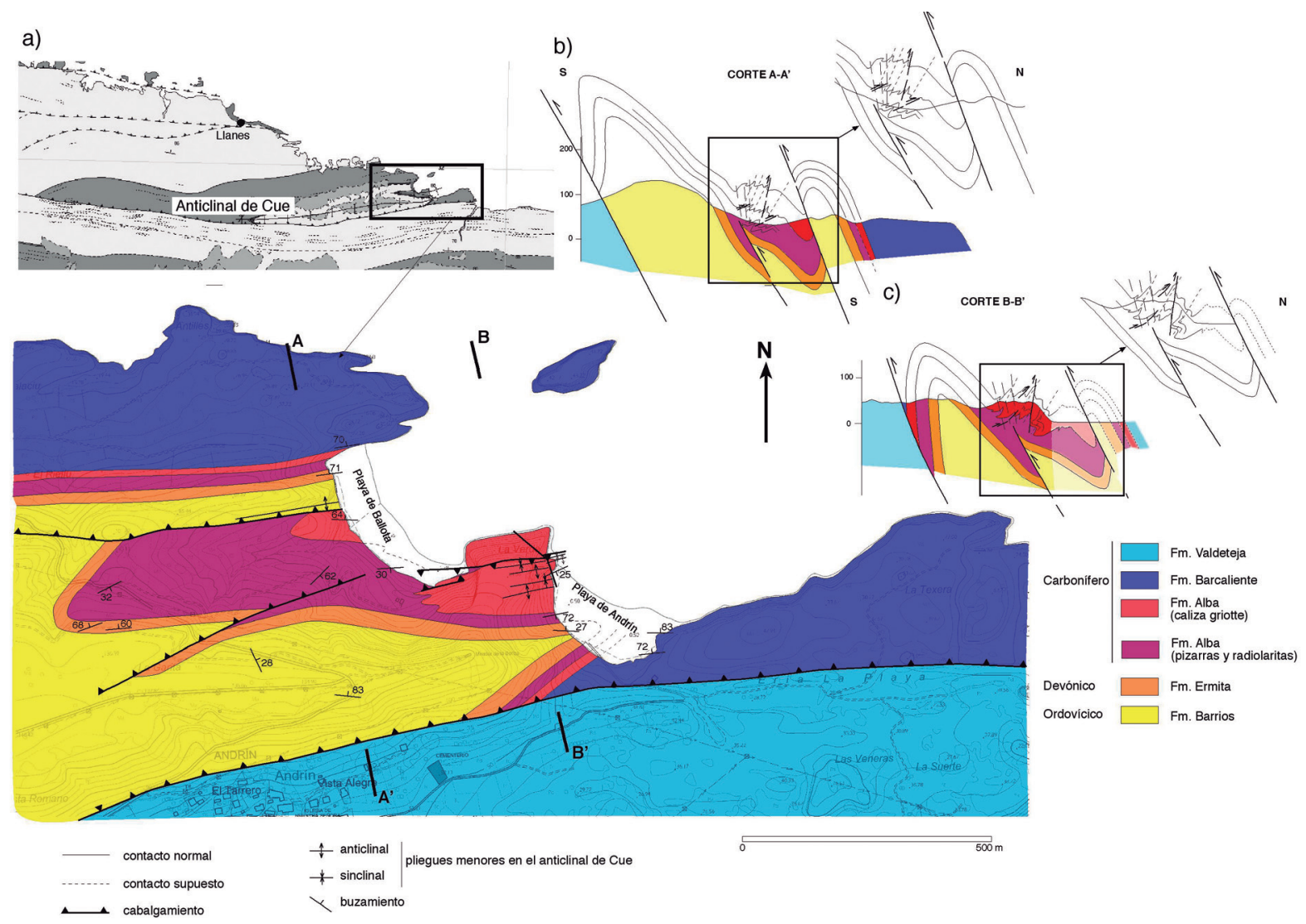

Figura 3. a) Mapa geológico de los alrededores de los acantilados de las playas de La Ballota y de Andrín, y b) y c) cortes geológicos del anticlinal de Cué. Los colores de las distintas unidades estratigráficas en la parte norte del corte geológico de la figura c) son más claros debidos a que está zona las capas están bajo el agua del Mar Cantábrico. Las zonas más complejas de ambos cortes geológicos se reproducen también en blanco y negro a fin de resaltar las estructuras. Esta región está ubicada en el esquema estructural de la figura 1. 
mientos están ubicados en la parte centro-oriental de la Zona Cantábrica y en la rama septentrional del Arco Astúrico, la cual está dominada en su parte norte por estructuras de orientación preferentemente E-O. Este afloramiento se sitúa en el flanco norte (trasero) del anticlinal de Cué (Martínez-García et al., 1981), el cual presenta un fuerte buzamiento hacia el norte, y en la zona de charnela de un sinclinal situado al norte del anticlinal (ver por ejemplo los mapas y cortes geológicos de Martínez-Álvarez, 1965; Martínez-García, 1980; Marquínez, 1989; Instituto Geológico y Minero de España, 2005-2011).

\section{Estratigrafía}

\section{Alrededores de San Emiliano}

En el afloramiento de los alrededores de San Emiliano, la Fm. Alba presenta una sucesión bastante completa de unos $30 \mathrm{~m}$ de espesor. Está formada en su parte inferior por aproximadamente $3,5 \mathrm{~m}$ de calizas nodulosas rojizas de tipo "wackestone» en facies "griotte» con esporádicos interestratos de pizarras rojas (Mb. Gorgera); una parte intermedia de unos $3 \mathrm{~m}$ de espesor constituida por radiolaritas y pizarras silíceas de colores variados (Mb. Lavandera); y una parte superior de alrededor de $23,5 \mathrm{~m}$ que se inicia con calizas nodulosas rojizas de tipo "wackestone» en facies "griotte», calizas de color gris claro de tipo «mudstone» y pizarras rojas y verdes y que se convierte en calizas gris claro de tipo «mudstone», con esporádicos interbancos de pizarras gris-verdosas, hacia la parte alta de la sucesión (Mb. Canalón) (Fig. 4). Son frecuentes los bioclastos de organismos marinos tales como plancton, ostrácodos, trilobites y goniatites (Rodríguez-Fernández et al., 1991). La Fm. Alba reposa sobre un nivel de unos pocos decímetros de espesor de pizarras gris oscuras con nódulos de manganeso ocasionales, cherts y areniscas que corresponde a la Fm. Vegamián, e inmediatamente por debajo de esta se encuentran las calizas de color claro y grano grueso de la Fm. Baleas. Por encima de la Fm. Alba se sitúa la Fm. Barcaliente formada por calizas gris oscuras de tipo «mudstone», si bien el contacto entre ambas formaciones está cubierto en este sector.

\section{Fm. Barcaliente}
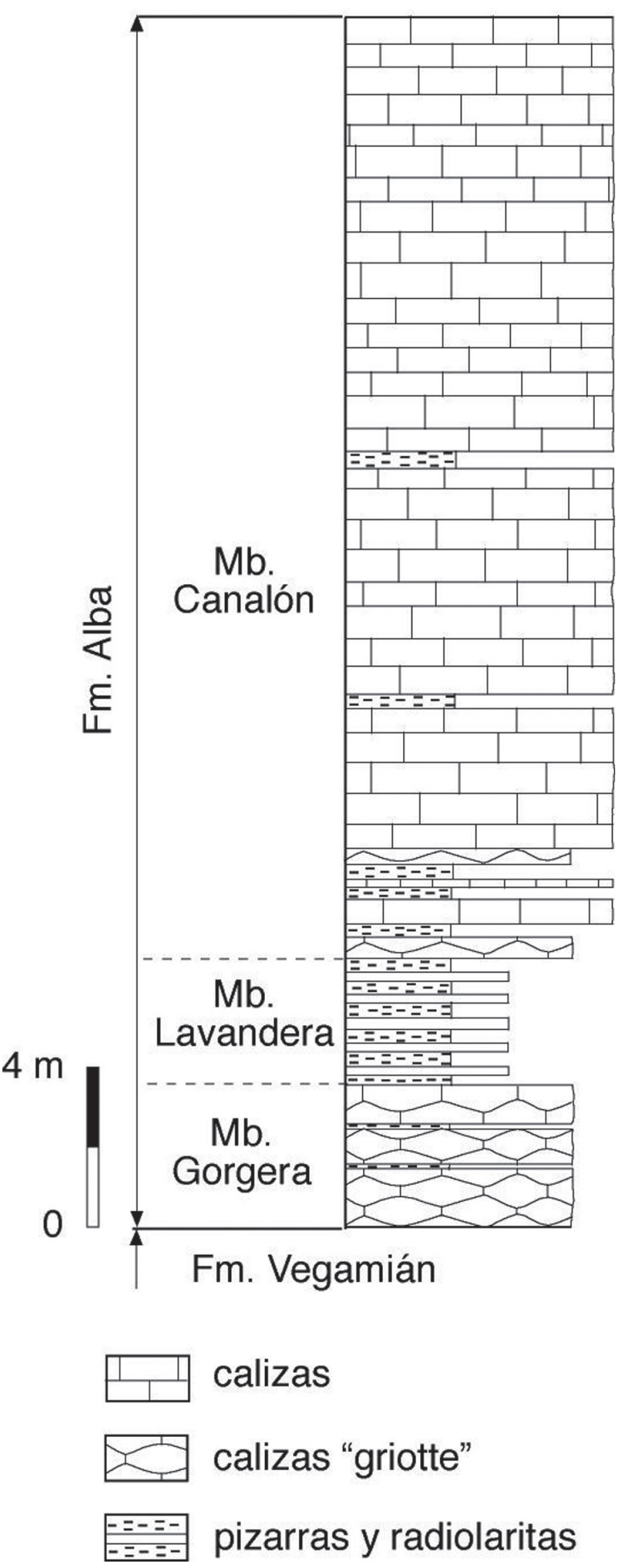

Figura 4. Columna estratigráfica sintética de la Fm. Alba en el afloramiento de San Emiliano. 
Alrededores de las playas de La Ballota y de Andrín

En la zona de los acantilados de las playas de La Ballota y de Andrín y alrededores no aflora la parte inferior de la Fm. Alba. El espesor total aproximado de esta unidad es muy difícil de determinar dado que se encuentra altamente deformada; a partir de los cortes geológicos parece que podría ser del orden de 35 a $40 \mathrm{~m}$, si bien este es un valor aproximado y tanto sobre el terreno como en el mapa geológico su espesor es aparentemente superior en muchas zonas del área cartografiada. Los términos más bajos de la serie que se reconocen son unos $17 \mathrm{~m}$ de pizarras y radiolaritas rojizas y algunos niveles de color gris verdoso, mientras que la parte superior, que alcanzaría unos $20 \mathrm{~m}$, está formada por calizas nodulosas rojizas de tipo "wackestone» en facies "griotte» con niveles de pizarras rojas (Fig. 5). Se reconocen restos de crinoideos, goniatítidos, ostrácodos, radiolarios y trilobites (Martínez-García et al., 1981). En esta zona, la Fm. Alba se encuentra sobre la Fm. Ermita, constituida por areniscas de grano medio grueso y microconglomerados de colores rojizos y amarillentos. Sobre la Fm. Alba se dispone una sucesión de calizas gris oscuro tableadas de tipo «mudstone» pertenecientes a la Fm. Barcaliente.

\section{Similitudes y diferencias entre ambos afloramientos}

En los dos afloramientos estudiados se han reconocido aproximadamente los mismos tipos de rocas (Fig. 4 y 5). No obstante la sucesión de rocas que conforman la Fm. Alba en ambos afloramientos es distinta dado que en los alrededores de San Emiliano presenta tres términos, mientras que en las playas de La Ballota y de Andrín afloran únicamente dos términos. Por otro lado el espesor de la Fm. Alba es distinto en ambos afloramientos siendo en las playas de La Ballota y de Andrín aproximadamente 1,3 veces superior al espesor de San Emiliano. Desde el punto de vista litológico parece razonable correlacionar el tramo de radiolaritas y pizarras entre ambos afloramientos (Mb. Lavandera) aunque en San Emiliano presente un espesor de $3 \mathrm{~m}$ y en las playas de La Ballota y de Andrín unos $17 \mathrm{~m}$. Si esto fuera correcto, el tramo de unos $20 \mathrm{~m}$ de calizas «griotte» $y$ pizarras situado sobre los niveles de radiolaritas y pizarras en las playas de La Ballota y de Andrín podría
Fm. Barcaliente

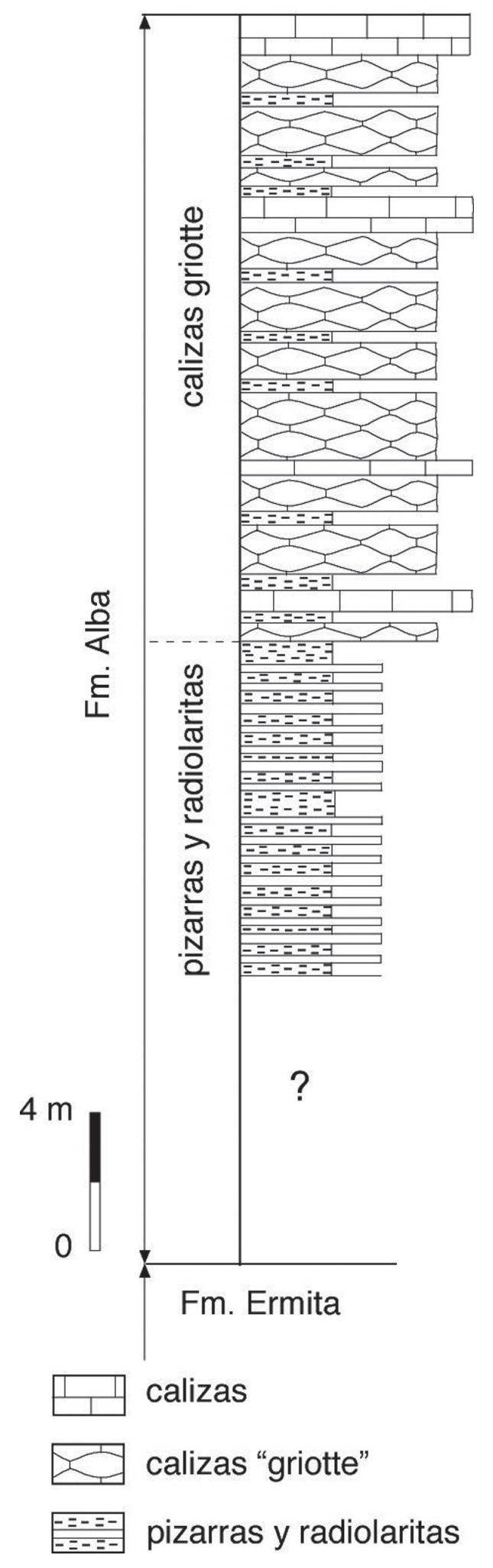

Figura 5. Columna estratigráfica sintética de la Fm. Alba en los afloramientos de las playas de La Ballota y de Andrín. 
corresponder a la parte mas baja del tramo superior del afloramiento de San Emiliano (Mb. Canalón) compuesto también por calizas "griotte» y pizarras y cuyo espesor es inferior a $3 \mathrm{~m}$. Sin embargo, hay que tener en cuenta que las calizas "griotte» y pizarras no son propias únicamente de la parte superior de la formación puesto que en el afloramiento de San Emiliano la parte inferior (Mb. Gorgera) también está compuesta por calizas «griotte» y pizarras.

Por lo que respecta a las rocas ubicadas por encima de la Fm. Alba, en ambos casos se trata de las calizas de la Fm. Barcaliente. Sin embargo, las rocas ubicadas bajo la Fm. Alba en la zona de San Emiliano son las pizarras de la Fm. Vegamián, aunque presentan muy poco espesor e inmediatamente debajo aparecen las calizas de la Fm. Baleas, mientras que en la zona de las playas de La Ballota y de Andrín se trata de las areniscas y microconglomerados de la Fm. Ermita.

Teniendo en cuenta que el afloramiento de San Emiliano se encuentra en la rama sur del Arco Astúrico y el afloramiento de las playas de La Ballota y de Andrín en la rama norte y que las direcciones de transporte tectónico deducidas por diversos autores en distintos puntos de la Zona Cantábrica van dirigidas hacia el interior del arco (ver entre otros Pérez-Estaún et al., 1988; Pérez-Estaún y Bastida, 1990; Aller et al., 2004; Alonso et al., 2009), eso significa que deshaciendo el transporte sufrido durante la orogenia varisca a fin de colocar estos afloramientos en sus posiciones previas y realizar así una pseudo-reconstrucción paleogeográfica, los afloramientos estudiados estaban inicialmente todavía mas alejados entre ellos de lo que están en la actualidad. Este hecho apoyaría la existencia de diferencias en la serie estratigráfica de la Fm. Alba entre ambos afloramientos.

\section{Estructura}

En este trabajo describiremos brevemente los pliegues de escala cartográfica en los que están inmersos los dos afloramientos a fin de encuadrarlos desde el punto de vista estructural en su marco regional. A continuación describiremos los pliegues de escala mesoscópica, a veces relacionados con cabalgamientos, que se reconocen en los dos afloramientos es- tudiados. Los pliegues coexisten con otro tipo de estructuras mucho menos abundantes, como por ejemplo un clivaje local, así como fallas, diaclasas y venas, cuyas relaciones angulares y temporales con los pliegues y cabalgamientos son variadas.

\section{Alrededores de San Emiliano}

Estructuras de escala cartográfica: El anticlinal de Villasecino, en el cual se ubica el afloramiento de los alrededores de San Emiliano, es un pliegue recto, apretado, de dimensiones kilométricas y de dirección aproximadamente E-O. Este anticlinal está afectado por abundantes fallas subverticales de dirección E-O, NE-SO y NO-SE, que llegan a alcanzar longitudes kilométricas, algunas de las cuales son posteriores al pliegue, dado que cortan y desplazan ambos flancos (Fig. 2). Se interpreta como un anticlinal que en superficie involucra una sucesión Cámbrico-Carbonífera (De Sitter, 1962; Marcos, 1968; Martínez-Álvarez et al., 1968; Alonso et al., 1989; Rodríguez-Fernández et al., 1990; Instituto Geológico y Minero de España, 2005-2011). Marcos (1968) considera que se trata de un pliegue longitudinal con respecto al sistema de cabalgamientos. Posteriormente, Bastida et al. (1984) y Alonso et al. (1989) dedujeron que el sentido de transporte tectónico durante la compresión varisca en unidades estructurales ubicadas al sur y al oeste de la zona estudiada estaba dirigido hacia el NE, por lo que el anticlinal de Villasecino, de orientación E-O, podría considerarse como una estructura oblicua.

Estructuras a escala de afloramiento: En el afloramiento ubicado en los alrededores de San Emiliano, por lo general las capas se inclinan del orden de $70-85^{\circ}$ hacia el NNE (Fig. 6a y b). De acuerdo con Masini et al. (2010a y b), la disposición actual de la mayoría de las estructuras no corresponde a la posición en la que se formaron sino que fueron basculadas tras su formación. Rotando el afloramiento hasta que la sucesión estratigráfica esté en posición normal (Fig. 6c) se obtiene una visión aproximadamente correcta de las estructuras y es como serán descritas a continuación, desde los términos inferiores a los términos superiores de la formación. La estructura que presenta cada uno de los tres miembros de la Fm. Alba es distinta. 

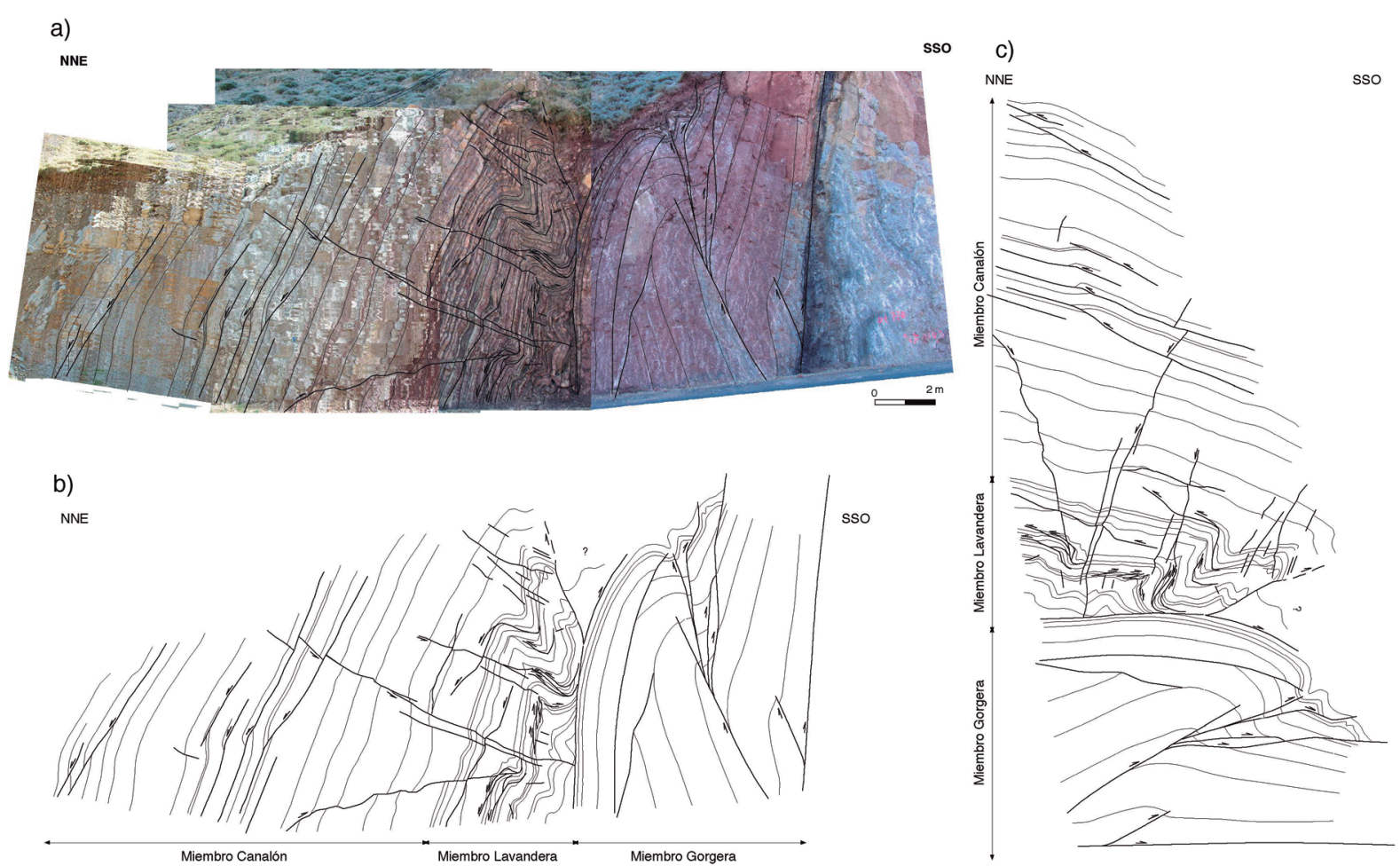

Figura 6. a) Montaje panorámico de fotografías del afloramiento de la Fm. Alba afectada por diversos tipos de pliegues relacionados con fallas en los alrededores de San Emiliano. De sur a norte (y de base a techo) se reconoce el miembro formado por calizas «griotte» (Mb. Gorgera), el miembro formado por radiolaritas y pizarras (Mb. Lavandera) y el miembro constituido por calizas "griotte» y calizas grises (Mb. Canalón). b) Interpretación fotogeológica de las fotografías ilustradas en a). c) Interpretación fotogeológica mostrada en b) rotada de tal forma que las capas inferiores de la sucesión de la Fm. Alba se disponen en posición horizontal y con la polaridad estratigráfica hacia arriba.

Las calizas en facies «griotte» de la parte inferior (Mb. Gorgera) están deformadas fundamentalmente por un antiforme paralelo y abierto, con charnela redondeada, de dimensiones decamétricas, asimétrico y con vergencia sur (Fig. 6). Este pliegue aparece en el bloque superior de un cabalgamiento de buzamiento moderado hacia el norte, dirigido hacia el sur y cuyo desplazamiento es de orden métrico. Cuando este cabalgamiento involucra la parte inferior de las calizas "griotte», estas se encuentran en situación de rellano de bloque superior sobre rampa de bloque inferior, pero en la parte superior de la sucesión el cabalgamiento se bifurca hacia el sur en un conjunto de cabalgamientos de desplazamiento muy inferior que colocan capas en situación de rampa de bloque superior sobre rampa de bloque inferior. En este sector donde el cabalgamiento principal se bifurca se reconocen también algunos pliegues de segundo orden. Tanto la geometría del pliegue, como su relación con los cabalgamientos, así como el hecho de que estos pierdan desplazamiento hacia la parte alta de la sucesión y aparezcan pliegues menores que compensen sus desplazamientos, sugiere que pueda ser interpretado como un pliegue de propagación de falla (Masini et al., 2010a, 2010b).

Un despegue separa las calizas «griotte» descritas de las alternancias de radiolaritas y pizarras del $\mathrm{Mb}$. Lavandera situadas en la parte media de la formación. Las radiolaritas y pizarras son rocas más dúctiles que las que constituyen los otros dos miembros de la Fm. Alba y acumulan más deformación. Las estructuras más evidentes son pliegues, tanto anticlinales como sinclinales, de escala métrica, asimétricos y con geometrías preferentemente angulosas (Fig. 6). Estos pliegues son vergentes al sur, cerrados en su mayoría y con superficies axiales que se inclinan moderadamente hacia el norte. En ellos se han reconocido numerosos cabalgamientos que implican poco desplazamiento y en su mayoría están plegados. Estos 
cabalgamientos se disponen fundamentalmente en las zonas de charnela de los pliegues o en los flancos, próximos a las zonas de charnela. La mayor parte de estos cabalgamientos se dirigen hacia el norte, si bien también los hay que se dirigen hacia el sur. Estas estructuras desarrolladas en las charnelas de los pliegues mayores dan lugar a repeticiones de capas y tienen a su vez pliegues menores asociados. Además, se han observado otros pliegues menores fundamentalmente desarrollados en las zonas de mayor curvatura de los de mayor escala. Todas estas estructuras desarrolladas en las zonas de charnela de los pliegues principales dan lugar a un engrosamiento de las mismas, más acusado en determinados niveles estratigráficos produciendo disarmonías. Es probable que tanto los cabalgamientos, y estructuras asociadas a estos, como los pliegues menores sean estructuras de acomodación simultáneas al desarrollo de los pliegues mayores de este miembro de la Fm. Alba.

Las capas de calizas de color gris claro de la parte superior (Mb. Lavandera) están plegadas en distintos niveles de la sucesión estratigráfica por anticlinales paralelos, suaves, con geometría redondeada y escala decimétrica, asimétricos y preferentemente vergentes hacia el norte (Fig. 6). Estos pliegues se ubican en el bloque superior de cabalgamientos subparalelos a la estratificación, que presentan algunos tramos de buzamiento suave hacia el sur, están dirigidos preferentemente hacia el norte y el desplazamiento que provocan es centimétrico a decimétrico. En estos cabalgamientos se reconocen tanto rellanos de bloque superior sobre rellanos o rampas de bloque inferior, como rampas de bloque superior sobre rellanos o rampas de bloque inferior. La geometría de los pliegues, así como las distintas situaciones de las capas en relación con los cabalgamientos, indica que se trata de pliegues de rampa, fundamentalmente pliegues de flexión de falla.

\section{Alrededores de las playas de La Ballota y de Andrín}

Estructuras de escala cartográfica: El anticlinal de Cué, del cual forman parte los afloramientos de las playas de La Ballota y de Andrín, es un pliegue casi isoclinal de dimensiones kilométricas y dirección E-O, cuyo eje buza hacia el este en la zona estudiada y cuyo plano axial buza fuertemente hacia el norte
(Fig. 3). Este anticlinal está situado en el bloque superior de un cabalgamiento de longitud kilométrica, de dirección aproximada E-O, fuerte buzamiento hacia el norte y sentido de movimiento hacia el sur. El anticlinal está probablemente relacionado con el cabalgamiento, de tal manera que podría tratarse de un pliegue de rampa. El flanco norte del anticlinal es a su vez el flanco común de un sinclinal de menores dimensiones. El flanco norte de este sinclinal está cortado por un cabalgamiento sobre el cual se dispone otro anticlinal también de dimensiones menores. En diversos mapas geológicos se observa que estas estructuras involucran una sucesión Ordovícico-Carbonífera en superficie (por ejemplo Martínez-García, 1980; Marquínez, 1989; Instituto Geológico y Minero de España, 2005-2011; De Ana, 2015) . Dado que en unidades estructurales al sur del anticlinal de Cué se ha deducido un sentido de transporte tectónico durante la compresión varisca hacia el SSW (Farias, 1982), es decir, subperpendicular a la traza del anticlinal de Cué, podemos inferir que este pliegue corresponde a una estructura frontal con respecto al sistema de cabalgamientos.

Estructuras a escala de afloramiento: Los términos más bajos de la Fm. Alba que afloran presentan una anchura de afloramiento muy superior a su espesor real, tanto en la playa de La Ballota como en la zona inmediatamente al oeste, que corresponde a una terminación periclinal de un sinclinal. Esto es debido en parte a cuestiones topográficas, pero también a estructuras que producen repeticiones. A pesar de la extensión cartográfica interpretada, estos términos inferiores apenas se observan y únicamente disponemos de algunos afloramientos discontinuos en la parte central de la playa de La Ballota. En ellos se reconocen numerosos anticlinales y sinclinales que muestran cambios de espesor de las capas, especialmente en las zonas de charnela, y que corresponden a pliegues desde cerrados a isoclinales, con geometrías preferentemente angulosas y de dimensiones métricas o inferiores (Fig. 7a). Se han reconocido tanto pliegues simétricos como asimétricos, mayoritariamente vergentes al norte, con planos axiales que buzan generalmente hacia el sur con bajo ángulo y ejes subhorizontales suavemente inclinados. También hay cabalgamientos que repiten estos niveles. Por ejemplo, se ha interpretado un cabalgamiento de rumbo ONO-ESE al oeste de la playa de La Ba- 


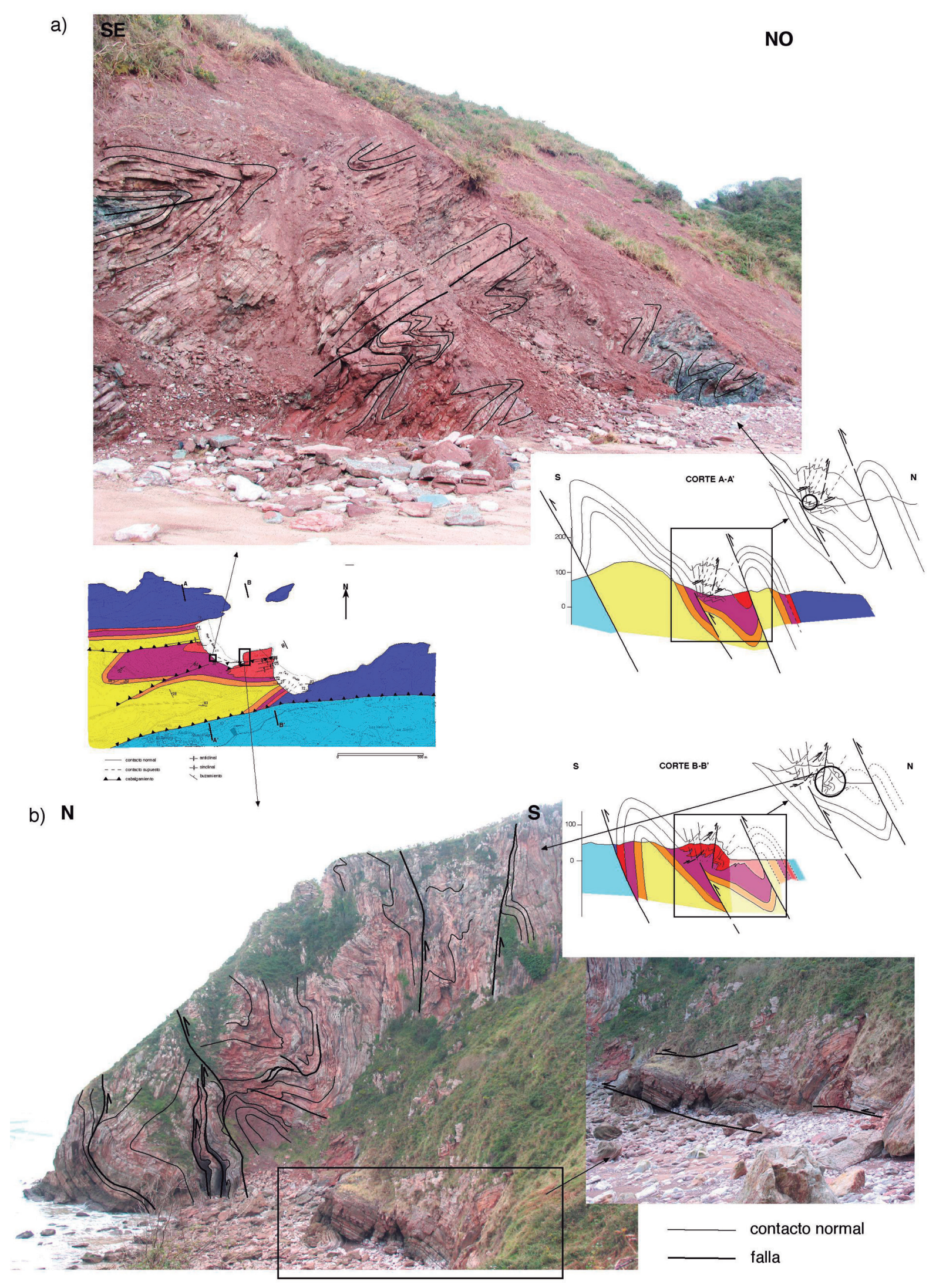






Figura 7. a) Fotografía de un afloramiento en la playa de La Ballota de los términos de radiolaritas y pizarras de la Fm. Alba (parte baja de la sucesión) afectados por pliegues, cuyas superficies axiales están suavemente inclinadas hacia el norte, y algunas fallas. b) Fotografía de un afloramiento en la playa de La Ballota de los términos de calizas "griotte» y pizarras de la Fm. Alba (parte alta de la sucesión) afectados por pliegues con superficies axiales subverticales en la parte sur y con superficies axiales horizontales en la parte norte separados por un cabalgamiento subvertical. c) Fotografía de un afloramiento en la playa de Andrín de los términos de calizas «griotte» y pizarras de la Fm. Alba (parte alta de la sucesión) afectados por interferencia de pliegues y fallas. El sistema de pliegues más antiguo presenta superficies axiales subhorizontales y el más moderno subverticales. La ubicación de las tres fotografías se muestra en imágenes reducidas del mapa y de los cortes geológicos extraídos de la Fig. 3.

llota, si bien en la playa no ha sido posible identificarlo, dirigido hacia el sur y que afecta también a la Fm. Barrios y a la Fm. Ermita. Existen además numerosos cabalgamientos dirigidos hacia el norte en el extremo oriental de esta playa donde afloran fundamentalmente las calizas "griotte», situadas por encima. Se interpreta que la mayoría de estos cabalgamientos llegan a afectar a las radiolaritas y pizarras y de hecho en algún caso superponen estos términos sobre las calizas (Fig. 7b). Estos cabalgamientos tienen un buzamiento bajo en la playa de La Ballota y se verticalizan hacia el acantilado oeste de la playa y/o niveles más altos de la serie.

La unidad superior de la Fm. Alba diferenciada en este sector, que consiste fundamentalmente en cali- zas "griotte», ocupa un extenso afloramiento entre las playas de La Ballota y de Andrín. En el acantilado que separa ambas playas se observan estas rocas afectadas por una intensa deformación (Fig. 7b y c). Las estructuras más numerosas son los pliegues métricos a decamétricos, generalmente redondeados, si bien se convierten en angulosos en el núcleo, con ejes subhorizontales o suavemente inclinados hacia el este o hacia el oeste. La mayoría de los pliegues son cerrados, aunque también se han observado algunos abiertos y, en menor número apretados. Existen además numerosos cabalgamientos, por lo general con direcciones aproximadamente E-O con inclinaciones muy variables, desde suaves hasta verticales, y sentido de movimiento tanto hacia el norte como hacia el sur, que localmente pueden llegar 
a involucrar en superficie los tramos de radiolaritas y pizarras. Uno de los cabalgamientos vergentes al norte, mencionados en el párrafo anterior, presente en la parte oriental de la playa de La Ballota, se ha representado en el mapa de la Fig. 3 extendiéndose hasta la playa de Andrín. Se trata de una falla inversa con un buzamiento elevado hacia el sur, dirigida hacia el norte, que corta y desplaza las calizas de la parte superior de la Fm. Alba a lo largo de unos pocos centenares de metros (Fig. 3a y c). Esta falla separa una zona situada en su bloque inferior (norte) donde, en zonas próximas a la falla, abundan los pliegues con superficies axiales desde suavemente inclinadas hacia el sur hasta subhorizontales, de una zona ubicada en su bloque superior (sur) en la cual, en zonas próximas a la falla, predominan los pliegues con superficies axiales desde fuertemente inclinadas hacia el sur a subverticales (Fig. $7 \mathrm{~b}$ y c). En el bloque superior de esta falla inversa, las superficies axiales de los pliegues fuertemente inclinadas hacia el sur a subverticales disminuyen su buzamiento hacia el sur, tal y como se observa en la parte oeste de la playa de Andrín. Esta disminución de buzamiento es causada por una superposición de antiformes y sinformes abiertos a suaves, con geometría redondeada y planos axiales desde fuertemente inclinados al norte a subverticales, dando lugar a interferencias de pliegues de tipo 3. La primera generación corresponde a los pliegues vergentes al norte y la segunda generación a los pliegues subverticales a vergentes al sur. Algunos de los pliegues están relacionados con los cabalgamientos coexistiendo en la zona los tres tipos principales: pliegues de flexión de falla, pliegues de propagación de falla y pliegues despegados. También se ha observado abundantes fallas inversas o cabalgamientos que se desarrollan como estructuras de acomodación de la deformación en los pliegues, como por ejemplo "out of synclines» en las zonas de charnela, por lo que en este caso se han interpretado como estructuras relacionadas con el plegamiento.

\section{Similitudes y diferencias entre ambos afloramientos}

En los dos afloramientos estudiados la Fm. Alba se encuentra en posiciones estructurales aproximadamente similares; en el flanco norte con fuerte buzamiento hacia el norte de anticlinales apretados y de orientación aproximadamente E-O de entidad cartográfica (Fig. 2 y 3). No obstante, mientras que el anticlinal de Villasecino corresponde a una estructura oblicua, el anticlinal de Cué corresponde a una estructura frontal.

En general, la deformación sufrida por la Fm. Alba en los alrededores de San Emiliano es inferior y menos dúctil que la sufrida en la zona de las playas de La Ballota y de Andrín, aunque ambos afloramientos tienen en común el hecho de que la deformación es más dúctil en los materiales pizarrosos y en las radiolaritas que en el caso de los niveles carbonatados (Fig. 6 y 7). La Fm. Alba acomoda deformación mediante el desarrollo de diversas estructuras a escala de afloramiento en los dos afloramientos estudiados y en ambos se han observado tanto pliegues de rampa como despegados. En las radiolaritas y pizarras de los dos afloramientos son frecuentes los pliegues despegados, mientras que en los niveles de calizas "griotte», aunque puedan presentar pliegues despegados, están desarrollados fundamentalmente otros tipos de pliegues, como los relacionados con rampas de cabalgamientos. En ambos afloramientos predominan los pliegues paralelos en las calizas «griotte» y habitualmente tienen un ángulo entre flancos superior al de los pliegues que afectan los niveles de radiolaritas y pizarras. Por lo general el ángulo entre flancos es mayor en los pliegues del sector de San Emiliano con respecto a los pliegues observados en las playas de La Ballota y de Andrín. En ambos afloramientos los pliegues de mayor tamaño son los desarrollados en paquetes que involucran calizas "griotte». A grandes rasgos, el tamaño y número de los pliegues desarrollados en el afloramiento de los alrededores de San Emiliano es inferior al de los pliegues presentes en los afloramientos de las playas de La Ballota y de Andrín.

\section{Evolución estructural}

\section{Alrededores de San Emiliano}

Con respecto a las relaciones entre los pliegues mesoscópicos identificados en el afloramiento de la Fm. Alba ubicado en los alrededores de San Emiliano y el anticlinal de Villasecino, sugerimos que los pliegues relacionados con fallas presentes en el afloramiento 
(Fig. 6) podrían haberse desarrollado en cualquiera de los estadios descritos a continuación.

a) Antes del comienzo de amplificación del anticlinal de Villasecino desvinculados de este. Suponiendo que esta hipótesis fuera cierta, su disposición original sería la que se obtendría mediante la rotación de unos $75^{\circ}$ a $80^{\circ}$ en sentido horario del afloramiento ilustrado en las figuras $6 \mathrm{a}$ y b empleando un eje aproximadamente perpendicular al afloramiento, es decir, de orientación ESE-ONO. Está rotación, ilustrada en la figura 6c, correspondería a devolver el flanco norte del anticlinal de Villasecino a su posición original antes de la formación del anticlinal empleando como eje de rotación el propio eje del anticlinal en este sector. La hipótesis de que estos pliegues menores pudieran corresponder a estructuras formadas en un estadio anterior al desarrollo del anticlinal de Villasecino, y por tanto, desligadas de este estaría apoyada por la presencia en la región de estructuras desarrolladas en distintos estadios. Así, Alonso et al. (1989) y Rodríguez-Fernández et al. (1991) sugieren que el cabalgamiento basal varisco de la unidad de Somiedo, que aflora al norte, sur y oeste del anticlinal de Villasecino formando una semi-ventana tectónica (De Sitter, 1962; Marcos, 1968; Martínez-Álvarez et al., 1968; Alonso et al., 1989; Rodríguez-Fernández et al., 1990; Instituto Geológico y Minero de España, 2005-2011), está plegado por el anticlinal de Villasecino.

b) Previamente al inicio del crecimiento del anticlinal de Villasecino pero asociados al desarrollo de este. Esta propuesta implica que estas estructuras menores podrían haber sido formadas mientras la estratificación se encontraba en posición horizontal durante un estadio de acortamiento paralelo a las capas precursor de la amplificación propiamente dicha del anticlinal de Villasecino. La existencia de una cierta cantidad de acortamiento paralelo a las capas antes del desarrollo de pliegues es un fenómeno documentado en muchas estructuras (ver por ejemplo Hudleston y Stephansson, 1973).

c) En el flanco norte del anticlinal de Villasecino como estructuras de acomodación del mecanismo de deslizamiento flexural («flexural-slip») ocurrido durante su amplificación. Se han identificado algunas estrías sobre las superficies de estratificación que indican un movimiento de las capas superiores paralelo a la línea de máxima pendiente de la estratificación; este movimiento es coherente con el sentido de transporte que se obtendría en el caso de que hubiera operado el mecanismo de "flexural slip» durante el desarrollo del pliegue de propagación de falla en las calizas "griotte» (Masini, 2007; Masini et al., 2010a 2010b). Esto indicaría que este mecanismo es posible en esta región. Si la hipótesis fuera correcta, la disposición original de las estructuras mesoscópicas oscilaría entre la mostrada en la figura $6 a$, suponiendo que se desarrollaron en las etapas iniciales de amplificación del anticlinal Villasecino, hasta posiciones entre la figura $6 \mathrm{c}$ y $6 \mathrm{~b}$, suponiendo que se desarrollaron en etapas de amplificación más avanzadas. No obstante, uno de los problemas que plantea esta hipótesis es que la mayoría de los pliegues relacionados con cabalgamientos desarrollados en la parte superior de la Fm. Alba son vergentes hacia el norte y por tanto, en principio, no serían coherentes con el mecanismo de "flexural slip» a escala del anticlinal de Villasecino.

\section{Alrededores de las playas de La Ballota y de Andrin}

De acuerdo con el mapa y los cortes de la figura 3 correspondientes a los afloramientos de la Fm. Alba en las playas de La Ballota y de Andrín se reconocen pliegues y cabalgamientos vergentes tanto al norte como al sur, así como figuras de interferencia de tipo 3. Estas estructuras se localizan en el flanco trasero del anticlinal de Cué (Fig. 3 y 7). Se proponen diversas hipótesis para explicar su origen.

a) Los pliegues podrían haberse desarrollado antes del comienzo de amplificación del anticlinal de Cué desvinculados de este y relacionados con los dos cabalgamientos más septentrionales reconocidos en la zona. En este caso, la evolución podría ser como la que se muestra en la figura 8. Primero se emplaza el cabalgamiento situado en posición más septentrional que afecta las cuarcitas de la Fm. Barrios y las areniscas de la Fm. Ermita en situación de rampa cabalgante y cabalgada. Los materiales de la Fm. Alba situados encima de las areniscas son muy dúctiles, de manera que cuando el cabalgamiento alcanza el contacto entre ambas unidades estratigráficas, donde hay un contraste mecánico muy acusado, se convier- 
a)

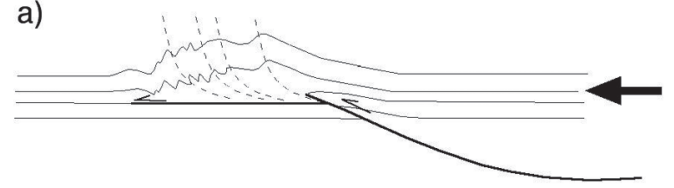

c)

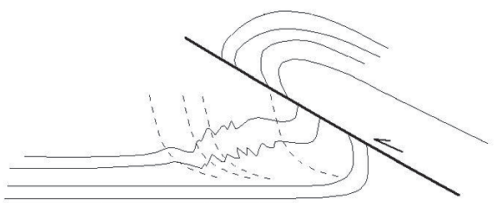

b)

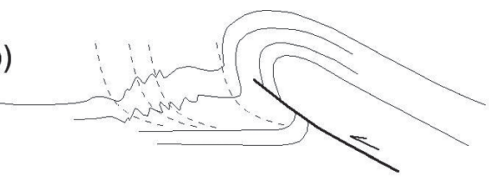

d)

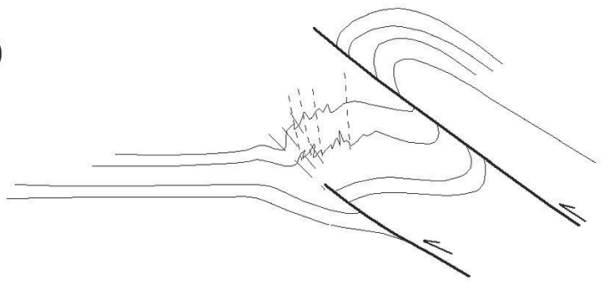

e)
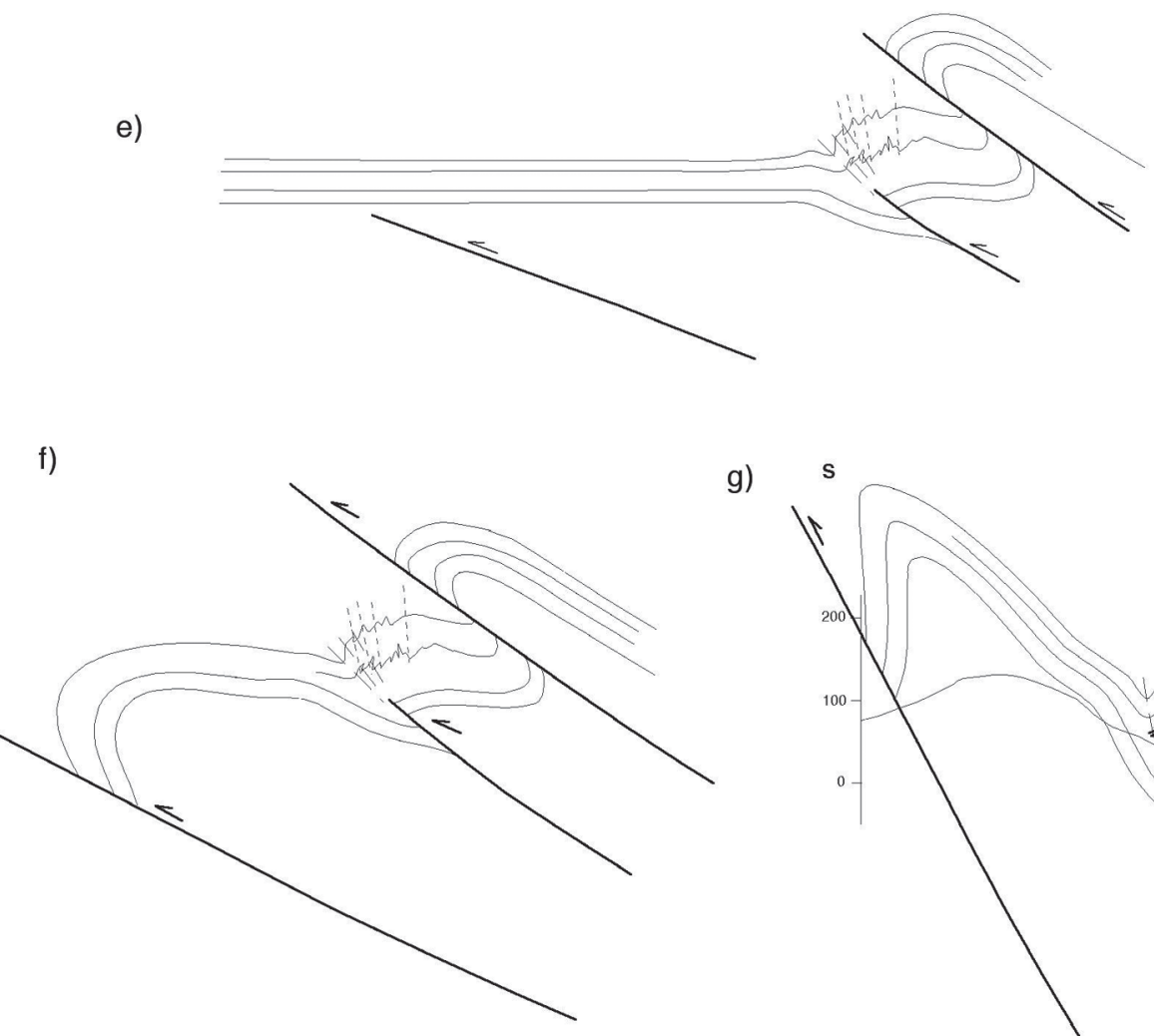

g)
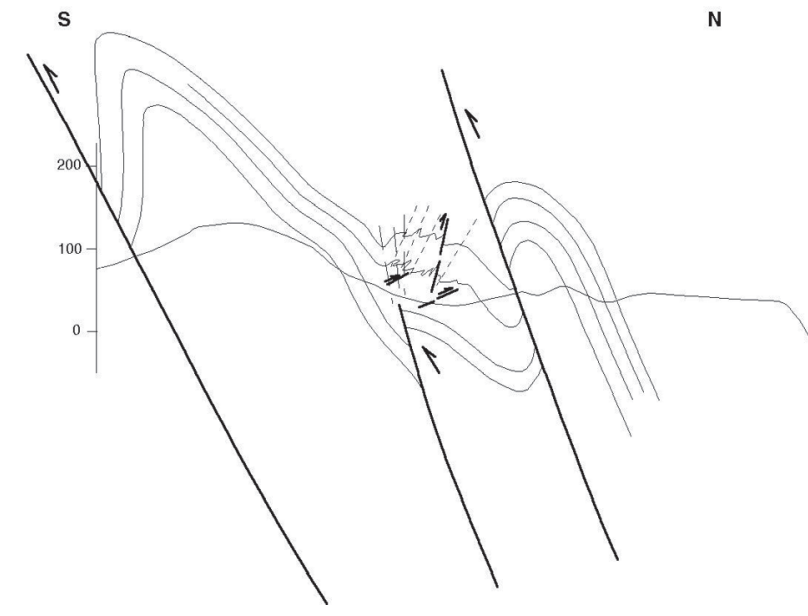

Figura 8. Esquema simplificado que ilustra la posible evolución de las estructuras que dieron lugar a la formación del anticlinal de Cué hasta llegar al estadio actual mostrado en los cortes geológicos de la Fig. 3.

te en un despegue por encima del cual se forman numerosos pliegues apretados con geometrías como las propuestas por Gray y Willman (1991), con trazas axiales verticales y geometría lístrica hacia el despegue (Fig. 8a). Posteriormente, el desplazamiento a lo largo del cabalgamiento aumenta y se forma un par anticlinal-sinclinal asociado (Fig. 8b y c). Asumiendo una secuencia de tipo "forward", en el bloque inferior de este cabalgamiento se emplaza un nuevo cabalgamiento y se genera un nuevo par de pliegues mayores asociados que producen una pequeña rotación de los pliegues menores anteriormente formados. El desplazamiento a lo largo de este nuevo cabalgamiento disminuiría hacia su terminación superior, de forma que este se acomodaría mediante una zona de intensa deformación dúctil dando lugar a pliegues con vergencia coherente con el sentido de movimiento del cabalgamiento. Estos deformarían a 
los pliegues menores de plano axial subvertical formados en la etapa previa, dando lugar a figuras de interferencia (Fig. 8d). Finalmente se emplazaría el cabalgamiento más meridional con el que se asocia el anticlinal de Cué (Fig. 8e y f). La disposición actual de toda la estructura es probablemente consecuencia, al menos en parte, del basculamiento debido al emplazamiento de nuevas estructuras hacia el sur (Fig. 8g).

b) Los pliegues menores actualmente vergentes al norte podrían ser el resultado de un acortamiento paralelo a las capas en los estadios previos al crecimiento del anticlinal de Cué, de igual manera a la propuesta b) en el afloramiento de San Emiliano. En este caso la deformación habría sido particularmente intensa en el flanco trasero del anticlinal, si bien no parece haber una razón que apoye la concentración de la deformación en este sector y no una distribución, mas o menos homogénea, a lo largo de todo el anticlinal. La vergencia norte que presentan actualmente estos pliegues sería debida al basculamiento sufrido por las capas en el flanco trasero del anticlinal de Cué, de manera que estos pliegues se habrían originado con planos axiales verticales. La evolución posterior se podría explicar de acuerdo al modelo propuesto en la figura 8 , eliminando el estadio representado en la figura $8 \mathrm{a}$.

c) Los pliegues vergentes al norte podrían haber sido originados durante el desarrollo del anticlinal de Cué en una zona de retrovergencia relativamente dúctil ubicada en el flanco trasero del anticlinal. En este sentido, la estructura general presentaría ciertas similitudes con algunos pliegues naturales (ver por ejemplo Alonso y Teixell, 1992) y experimentales (ver por ejemplo Huiqi et al., 1992) generados en el bloque superior de cabalgamientos, los cuales incluyen retrocabalgamientos o zonas de cizalla desarrolladas en el flanco trasero. En este caso, para explicar las figuras de interferencia de los pliegues el cabalgamiento central, junto con sus pliegues asociados, sería el más reciente en desarrollarse.

\section{Similitudes y diferencias entre ambos afloramientos}

En los dos afloramientos estudiados las historias estructurales podrían ser parecidas hasta cierto punto; los pliegues de escala mesoscópica desarrollados en el seno de la Fm. Alba son anteriores o en todo caso simultáneos a los pliegues regionales de escala cartográfica, en ambos casos se observan tanto cabalgamientos como pliegues con sentidos de movimiento y vergencias opuestas, y estas estructuras sufrieron rotaciones posteriores en parte como consecuencia de los pliegues regionales, No obstante, la historia estructural es más compleja en la zona de las playas de La Ballota y de Andrín donde se observan dos generaciones de pliegues que dan lugar a figuras de interferencia, siendo los de vergencia norte anteriores a los subverticales de vergencia sur. También en los afloramientos de las playas de La Ballota y de Andrín se ha reconocido algún cabalgamiento dirigido hacia el norte que corta a los pliegues y por tanto son posteriores a estos. Por el contrario en el afloramiento de San Emiliano no hay evidencias de diacronía entre las estructuras de vergencia norte y sur ni entre pliegues y cabalgamientos.

\section{Edad de la deformación}

En los afloramientos estudiados no existen criterios para determinar la edad de las estructuras, salvo el hecho de que todas están desarrolladas en materiales carboníferos. Tanto el anticlinal de Villasecino como el de Cué, así como los pliegues y cabalgamientos descritos en los afloramientos de San Emiliano y de las playas de La Ballota y de Andrín, se interpretan como estructuras de carácter compresivo formadas durante el Paleozoico a causa de la orogenia varisca. El hecho de que algunas estructuras sean posteriores a otras, como por ejemplo algunos cabalgamientos identificados en el acantilado que separa las playas de La Ballota y de Andrín los cuales son posteriores a los pliegues, se atribuye a su desarrollo en etapas tardías de la deformación principal varisca.

No obstante, no puede descartarse un posible reapretamiento de los pliegues, así como un rejuego de los cabalgamientos y/o formación de nuevas estructuras durante la orogénesis alpina de edad cenozoica tal y como se ha documentado en diversos puntos de la Zona Cantábrica (Pulgar et al., 1999 entre otros). Así pues, en zonas muy próximas las playas de La Ballota y de Andrín algunos cabalgamientos de dirección E-O afectan a rocas mesozoicas (ver por ejem- 
plo Martínez-García, 1980; Marquínez, 1989). La actividad alpina de algunos pliegues y cabalgamientos se vería apoyada por medidas tomadas en afloramientos de rocas post-paleozoicas pertenecientes a la Cuenca Asturiana que reposan discordantemente sobre el zócalo varisco de la Zona Cantábrica, ubicados al noreste del afloramiento de San Emiliano y al este del afloramiento de las playas de La Ballota y de Andrín. Así, la dirección de acortamiento durante la compresión alpina, determinada mediante análisis poblacional de fallas, es aproximadamente N-S (Lepvrier y Martínez-García, 1990; Uzkeda et al., 2016), es decir, aproximadamente perpendicular a la traza de las estructuras cartografiadas en ambos afloramientos.

\section{Condiciones de la deformación}

Las condiciones de presión y temperatura bajo las que se desarrollaron las estructuras presentes en ambos afloramientos correspondían a la zona diagenética tal y como se explica a continuación.

\section{Alrededores de San Emiliano}

Una sección geológica de escala regional de Rodríguez-Fernández et al. (1990), la cual atraviesa el área de estudio de San Emiliano, muestra que el espesor mínimo de la sucesión estratigráfica carbonífera por encima del afloramiento estudiado habría sido de alrededor de 1,5 km. Esta cifra podría corresponder a una profundidad mínima de enterramiento. El afloramiento estudiado se encuentra en el bloque inferior del cabalgamiento basal de la unidad varisca llamada Somiedo, que aflora al norte, sur y oeste del anticlinal de Villasecino formando una semi-ventana tectónica. Este cabalgamiento, que transporta en su bloque superior toda la sucesión paleozoica de más de $2 \mathrm{~km}$ de espesor, está plegado por el anticlinal Villasecino, lo que sugiere que la lámina cabalgante de Somiedo podría haber estado también situada sobre el afloramiento estudiado y la sucesión carbonífera que lo recubría en el momento en que se formaron los pliegues descritos. Por tanto, el espesor de las rocas por encima de las estructuras estudiadas en el momento en que desarrollaron oscilaría entre 1,5 y 3,5 kilómetros. Estos valores son coherentes con el índice de Kübler de illita (KI) y el índice de alteración del color de los conodontos (CAI) obtenidos, que indican que el afloramiento se encuentra en una región considerada como diagenética, es decir, no metamórfica (García-López et al., 1999, 2007).

\section{Alrededores de las playas de La Ballota y de Andrín}

Por lo que respecta a los afloramientos de las playas de La Ballota y de Andrín, una sección geológica de escala regional de Martínez-García (1980) muestra que el espesor mínimo de la sucesión estratigráfica carbonífera ubicada por encima del afloramiento estudiado podría haber sido de alrededor de 1,8 $\mathrm{km}$. Este espesor probablemente fue superior, pero es difícilmente estimable dado que desconocemos cuanto espesor de la parte superior de la sucesión carbonífera fue erosionado en este sector, dado que las rocas cretácicas descansan discordantemente sobre los materiales carboníferos. Este espesor mínimo está de acuerdo con el índice de Kübler de illita (KI) y el índice de alteración del color de los conodontos (CAI) obtenidos en esta región por Blanco-Ferrera et al. (2011), los cuales indican que el afloramiento estudiado se ubica en una zona diagenética.

\section{Conclusiones}

Las estructuras desarrolladas en la Fm. Alba presentan una serie de similitudes entre los afloramientos de los alrededores de San Emiliano y de las playas de La Ballota y de Andrín, tales como las rocas suprayacentes, la posición estructural, la presencia de pliegues de rampa y despegados, la presencia de estructuras con vergencias opuestas, la relación temporal entre pliegues y cabalgamientos de escala mesoscópica y pliegues cartográficos, la edad de las estructuras y las condiciones de presión y temperatura. No obstante, se han identificado también diversas diferencias entre ambos afloramientos, como por ejemplo, el hecho de que los términos que componen la sucesión estratigráfica, su espesor y las rocas infrayacentes son algo diferentes, las relaciones temporales entre las estructuras de vergencia norte y de vergencia sur y la cantidad de deformación y ductilidad. Aparentemente, las características estratigráficas deben haber ejercido una mayor influencia en el desarrollo de la 
deformación en el afloramiento de San Emiliano que en el de las playas de La Ballota y de Andrín, en las cuales, la presencia de dos cabalgamientos en el flanco norte del anticlinal de Cué podrían haber sido determinantes en la formación de dos generaciones de pliegues menores. Además, no podemos obviar el hecho de que existen factores no contemplados en este trabajo, como por ejemplo los mecanismos de formación de los anticlinales de Villasecino y Cué y de que tipo de pliegues se trata, los cuales podrían haber controlado de algún modo las características y evolución de los pliegues mesoscópicos observados en los afloramientos estudiados.

En ambos afloramientos existen una serie de rasgos estructurales directamente relacionados con las propiedades reológicas de las rocas involucradas en la deformación, de tal manera que estos responden a la estratigrafía mecánica. Así, en los tramos carbonatados de la Fm. Alba con calizas «griotte» se suelen desarrollar pliegues asociados a rampas de cabalgamientos aunque coexistan con otro tipo de pliegues, hay tanto pliegues paralelos como con cambios de espesor y el comportamiento general es mixto dúctil-frágil. Por el contrario, en los tramos de radiolaritas y pizarras suelen predominar los pliegues despegados con cambios de espesor, el ángulo entre flancos de los pliegues es mas bajo y el comportamiento es dúctil.

Este trabajo intenta ser un primer paso en la comprensión del comportamiento reológico de la Fm. Alba en diversos sectores de la cordillera. Para avanzar en esta línea de investigación, se requiere un análisis estructural detallado de esta unidad estratigráfica en otras áreas de la Zona Cantábrica y su comparación entre aquellas regiones donde presente idéntica estratigrafía, estructura y condiciones de desarrollo de las estructuras a fin de entender cuales son las características y de que forma influyen en su comportamiento.

\section{Agradecimientos}

M. Bulnes, cuya tesis doctoral fue codirigida por Alberto Marcos Vallaure, y J. Poblet, que compartió la edición de la revista Trabajos de Geología con Alberto durante 10 años, desean agradecerle su tra- bajo y dedicación desde el punto de vista docente, investigador y de gestión durante todos estos años y le dedican el presente artículo en este volumen. Los comentarios y sugerencias de Fernando Bastida y Joaquina Álvarez-Marrón han contribuido notablemente a la mejora de la versión inicial de este manuscrito. Este trabajo se integra en el marco del proyecto CGL 2011-23628 (Desarrollo de fracturas y venas Asociadas al plegamiento -FRAVEPLE-), financiado por el Ministerio de Ciencia e Innovación, y del proyecto CGL2015-66997-R (Aplicación del análisis del plegamiento a la investigación de recursos geológicos -AAPLIREgE-), financiado por el Ministerio de Economía y Competitividad y el Fondo Europeo de Desarrollo Regional (FEDER). También queremos agradecer a J. L. Alonso el mostrarnos uno de los afloramientos estudiados, a J. G. Antuña el mantenimiento del software para la interpretación estructural y a I. Moriano el habernos acompañado durante alguna campaña de campo. El estudio presentado en este artículo corresponde parcialmente al Trabajo de Investigación de M. Masini, equivalente al Diploma de Estudios Avanzados (DEA), y al Trabajo de Fin de Máster de A. de Ana.

\section{Bibliografía}

Adrichem Boogaert, H. A. van (1965): Conodont-bearing formations of Devonian and Lower Carboniferous age in the northern León and $\mathrm{Pa}-$ lencia (Spain). Leidse Geologische Mededelingen, 31: 165-178.

Aller, J., Álvarez-Marrón, J., Bastida, F., Bulnes, M., Heredia, N., Marcos, A., Pérez-Estaún, A., Pulgar, F. J. A. y Rodríguez-Fernández, R. (2004): Estructura, deformación y metamorfismo (Zona Cantábrica), en J. A. Vera (ed.), Geología de España. Sociedad Geológica de España-Instituto Geológico y Minero de España, Madrid, 42-49.

Alonso, J. L. (1989): Síntesis cartográfica de la región del manto del Esla. Trabajos de Geología, 18: 155-163.

Alonso, J. L. y Teixell, A. (1992): Forelimb deformation in some natural examples of fault-propaga- 
tion folds, en K. McClay, K. (ed.), Thrust Tectonics. Chapman \& Hall, Londres, 175-180.

Alonso, J. L., Álvarez-Marrón, J. y Pulgar, J. A. (1989): Síntesis cartográfica de la parte sudoccidental de la Zona Cantábrica. Trabajos de Geología, 18: 145-155.

Alonso, J. L., Álvarez-Marrón, J., Aller, J., Bastida, F., Farias, P., Marcos, A., Marquínez, J., Pérez-Estaún, A. y Pulgar, J. A. (1992): Estructura de la Zona Cantábrica. Universidad de Extremadura, Badajoz: 423-434.

Alonso, J. L., Marcos, A. y Suárez-Rodríguez, A. (2009): Paleogeographic inversion resulting from large out of sequence breaching thrusts: the León Fault (Cantabrian Zone, NW Iberia). A new picture of the external Variscan thrust belt in the Ibero-Armorican Arc. Geologica Acta, 7(4): 451-473.

Álvarez-Marrón, J., Heredia, N. y Pérez-EsTAÚn, A. (1989): Síntesis cartográfica de la Región del Ponga. Trabajos de Geología, 18: 127-137.

BARrois, C. (1882): Recherches sur las terrains anciens des Asturies et de la Galice. Mémoires du Société géologique du Nord, 2(I): 1-630.

Bastida, F. y Gutiérrez, G. (1989): Síntesis cartográfica de las unidades occidentales de la Zona Cantábrica. Trabajos de Geología, 18: 117-127.

Bastida, F., Marcos, A., Pérez-Estaún, A. y PulGAR, J. A. (1984): Geometría y evolución estructural del Manto de Somiedo (Zona Cantábrica, NO España). Boletín Geológico y Minero, XCV-VI: 517-539.

Belka, Z. y Lehman, J. (1998): Late Viséan/early Namurian conodont succession from the Esla area of the Cantabrian Mountains, Spain. Acta Geologica Polonica, 48: 31-41.

Blanco-Ferrera, S., Sanz-López, J., GarCía-López, S., Bastida, F. y Valín, M. L. (2011): Conodont alteration and tectonothermal evolution of a diagenetic unit in the Iberian Variscan belt (Ponga-Cuera unit, NW Spain). Geological Magazine, 148(1): 35-49.
Colman-Sadd, S. P. (1978): Fold development in Zagros simply folded belt, southwest Iran. AAPG Bulletin, 62(6): 984-1003.

Colmenero, J. R., Fernández, L. P., Moreno, C., Bahamonde, J. R., Barba, P., Heredia, N. y GonZÁLEZ, F. (2002): Carboniferous, en Gibbons, W. y Moreno, T. (eds.): Geology of Spain. Geological Society of London: 93-116.

Comte, P. (1959): Recherches sur les terrains anciens de la Cordillère Cantabrique. Memorias del Instituto Geológico y Minero de España, 60: 1-440.

De AnA, A. (2015): Estructura de los materiales paleozoicos entre las localidades de Llanes y Andrin (Unidad del Ponga, Zona Cantábrica). Trabajo de fin de Máster, Universidad de Oviedo, 30 p.

De Sitter, L. U. (1962): The structure of the southern slope of the Cantabrian Mountains. Geological map with section scale 1:100,000. Leidse Geologische Medelelingen, 26: 255-264.

FARIAS, P. (1982): La estructura del sector central de los Picos de Europa. Trabajos de Geología, 12: 63-72.

Fernández, L. P. (1995): El Carbonífero, en Aramburu, C. y Bastida, F. (eds.), Geología de Asturias. Ediciones Trea S. L.: 63-80.

Fernández, L. P., Bahamonde, J. R., Barba, P., Colmerero, J. R., Heredia, R., Rodríguez-Fernández, L. R., Salvador, C., Sánchez de Posada, L. C., Villa, E., Merino-Tomé, O. y Motis, K. (2004): Secuencia sinorogénica (Zona Cantábrica), en J. A. Vera (ed.), Geología de España. Sociedad Geológica de España-Instituto Geológico y Minero de España, Madrid, 34-42.

García López, S., y Sanz López, J. (2002): Devonian to Lower Carboniferous conodont biostratigraphy of the Bernesga Valley section (Cantabrian Zone, North Spain). Paleozoic Conodonts from Northern Spain. Serie Cuadernos del Museo Geominero, Instituto Geológico y Minero de España, 1: 163-205.

García-López, S., Bastida, F., Brime, C., Aller, J., Valín, M. L., Sanz-López, J., Méndez, C. A. 
y Menéndez-Álvarez, J. R. (1999): Los episodios metamórficos de la Zona Cantábrica y su contexto estructural. Trabajos de Geología, 21: 177-189.

García-López, S., Brime, C., Valín, M. L., SanzLópez, J., Bastida, F., Aller, J. y Blanco-Ferrera, S. (2007): Tectonothermal evolution of a foreland fold and thrust belt: the Cantabrian Zone (Iberian Variscan belt, NW Spain). Terra Nova, 19(6): 469475.

Gray, D. R. y Willman, C. E. (1991): Thrust-related strain gradients and thrusting mechanisms in a chevron-folded sequence, southeastern Australia. Journal of Structural Geology, 13(6): 691-710.

Higgins, A. C. (1974): Conodont zonation of the Lower Carboniferous of Spain and Portugal, en Bouckaert, J. and Stree, M. (eds.), International Symposium of Belgian Micropaleontological limits. Geological Survey of Belgium, 4, 17 p.

Hudleston, P. J. y Stephansson, O. (1973): Layer shortening and fold-shape development in the buckling of single layers. Tectonophysics, 17(4): 299-321.

Huiqi, L., McClay, K. R. y Powell, D. (1992): Physical models of thrust wedges, en K. McClay (ed.), Thrust tectonics. Chapman \& Hall, Londres, 71-81.

Instituto Geológico y Minero de España (2005-2011): Mapa geológico continuo de España 1:50.000 (Plan Geode). http://www.igme.es

Julivert, M. (1971): Décollement tectonics in the Hercynian Cordillera of NW Spain. American Journal of Science, 270: 1-29.

Julivert, M. (1979): A cross-section though the northern part of the Iberian Massif: its position within the Hercynian fold belt. Krystalinikum, 14: 51-67.

Julivert, M. (1981): A cross-section though the northern part of the Iberian Massif. Geologie en Minbouw, 60: 107-128.

Julivert, M. (1983): La estructura de la Zona Cantábrica, en J. A. Comba (ed.), Geología de España.
Libro Jubilar J. M. Ríos, Tomo I. Instituto Geológico y Minero de España, Madrid, 339-381.

Julivert, M., Fontboté, J. M., Ribeiro, A. y Conde, L. E. (1972): Mapa Tectónico de la Península Ibérica y Baleares, escala 1:1.000.000. Instituto Geológico y Minero de Espańa, Madrid.

Kullman, J., Reuther, C. D. y Schönenberg, R. (1977): La transición del estado geosinclinal a la orogénesis en la formación varisca de la Cordillera Cantábrica. Breviora Geologica Astúrica, 21: 4-11.

Lepvrier, C. y Martínez-García, E. (1990) Fault development and stress evolution of the post-Hercynian Asturian basin (Asturias and Cantabria, northwestern Spain). Tectonophysics, 184: 345-356.

Lotze, F. (1945). Zur gliederung der varisziden der Iberischen Meseta. Geotektonische Forschungen, 6: 78-92.

Marcos, A. (1968): La tectónica de la Unidad de La Sobia-Bodón. Trabajos de Geología, 2: 59-87.

Marquínez, J. (1989): Síntesis cartográfica de la Región del Cuera y los Picos de Europa. Trabajos de Geología, 18: 137-145.

Martínez Álvarez, J. A. (1965): Rasgos geológicos de la zona oriental de Asturias. Instituto de Estudios Asturianos, Diputación Provincial de Oviedo, 132 p.

Martínez Álvarez, J. A., Gutiérrez Claverol, M. y Vargas Alonso, I. (1968): Esquema geológico de la zona de la Cordillera Cantábrica comprendida entre los Puertos "Pajares» y "Ventana» (Asturias-León). Cátedra de Geología, Escuela de Minas de Oviedo.

Martínez-García, E. (1980): Mapa geológico de España. Escala 1:50.000. Hoja: 32 (16-04) Llanes. Instituto Geológico y Minero de España, Madrid.

Martínez-García, E., Corrales, I., Valladares, I., Méndez, I., Ramírez del Pozo, J., van Ginkel, A. C., Lamolda, M., Moreno de Castro, E. y Marcos, A. (1981): Memoria del mapa geológico de España. Escala 1:50.000. Hoja: 32 (16-04) Llanes. Instituto Geológico y Minero de España, Madrid, 40 p. 
Masini, M. (2007): Strain prediction using cross-section restoration: examples from the Appenines and Cantabrian Mountains. Trabajo de investigación, Universidad de Oviedo, 133 p.

Masini, M., Bulnes, M. y Poblet, J. (2010a): Cross-section restoration: a tool to simulate deformation. Application to a fault-propagation fold from the Cantabrian fold and thrust belt, NW Iberian Peninsula. Journal of Structural Geology, 32: 172-183.

Masini, M., Poblet, J. y Bulnes, M. (2010b): Structural analysis and deformation architecture of a fault-propagation fold in the southern Cantabrian Mountains, NW Iberian Peninsula. Trabajos de Geología, 30: 55-62.

Menéndez Álvarez, J. R. (1978): Conodontos de la Formación Genicera en el corte de Entrago (Teverga, Asturias). Breviora Geológica Astúrica, 22 (12): $1-7$.

Menéndez Álvarez, J. R. (1991): Conodontos del Carbonifero inferior y medio de la Cordillera Cantábrica. Tesis Doctoral, Universidad de Oviedo, 283 p.

Pérez-Estaún, A. y Bastida, F. (1990): Cantabrian Zone: structure, en Dallmeyer, R. D. y Martínez-García, E. (eds.), Pre-Mesozoic Geology of Iberia. Springer-Verlag, Berlin: 55-69.

Pérez-Estaún, A., Bastida, F., Alonso, J. L., MarQuínez, J., Aller, J., Álvarez-Marrón, J., Marcos, A. y Pulgar, F. J. A. (1988): A thin-skinned tectonics model for an arcuate fold and thrust belt: the Cantabrian Zone (Variscan Ibero-Armorican Arc). Tectonics, 7: 517-537.

Pulgar, J. A., Alonso, J. L., Espina, R. G. y MaRÍN, J. A. (1999): La deformación alpina en el basamento varisco de la Zona Cantábrica. Trabajos de Geología, 21: 283-294.

Ramsay, J. G. y Huber, M. I. (1987): The techniques of modern structural geology. Volume 2: folds and fractures. Academic Press, London, 700 p.

Rodríguez-Fernández, L. R., SuÁrez-Rodríguez, A., Toyos, J. M., López-Díaz, F., Heredia,
N. y Gutiérrez-Alonso, G. (1990): Mapa geológico de España. Escala 1:50.000. Hoja: 102 (12-7) Los Barrios de Luna. Instituto Tecnológico GeoMinero de España, Madrid, 130 p.

Rodríguez-Fernández, L. R., Barba, P., Fernández, L. P., Bardají, T., Silva, P. G., Suárez Rodríguez, A., Heredia, N., Gallastegui, G., Paniagua, A., Galán, L., Martínez-Álvarez, J. A., Torres Alonso, M., Gutiérrez Claverol, M., López Díaz, F., Toyos, J. M., Villa, E., Salvador González, C. y Bravo Fernández, I. (1991): Memoria del mapa geológico de España. Escala 1:50.000. Hoja: 102 (12-7) Los Barrios de Luna. Instituto Tecnológico GeoMinero de España, Madrid, $130 \mathrm{p}$.

Sánchez de Posada, L. C., Martínez Chacón, M. L., Méndez Fernández, C., Menéndez Álvarez, J. R., Truyols, J. y Villa, E. (1990): Carboniferous pre-Stephanian rocks of the Asturian-Leonese domain (Cantabrian Zone), en Dallmeyer, R. D. y Martínez-García, E. (eds.), Pre-Mesozoic Geology of Iberia. Springer-Verlag, Berlin: 24-33.

Savage, J. F. (1979): The Hercynian orogeny in the Cantabrian mountains, Northern Spain. Krystalinikum, 14: 91-108.

Savage, J. F. (1981): Geotectonic cross-section through the Cantabrian mountains, northern Spain. Geologie en Mijnbouw, 81: 3-5.

Uzkeda, H., Bulnes, M., Poblet, J., García-Ramos, J. C. y Piñuela, L. (2016): Jurassic extension and Cenozoic inversion tectonics in the Asturian Basin, NW Iberian Peninsula: 3D structural model and kinematic evolution. Journal of Structural Geology, 90: 157-176.

Wagner, R. H., Winkler Prins, C. J. y Riding, R. E. (1971): Lithostratigraphic unis of the lower part of the Carboniferous in northern León, Spain. Trabajos de Geología, 4: 603-663.

Wagner Gentis, C. H. T. (1980): Goniatites from the Visean-Namurian junctions beds in Palencia, NW Spain. Scripta Geologica, 55: 1-43. 